\title{
Neuromedin U Induces Pulmonary Group 2 Innate Lymphoid Cell Activation via NMUR1 Pathway During Acute Respiratory Syncytial Virus Infection
}

Weiwei LIU

China Medical University https://orcid.org/0000-0001-8479-9670

Si Wang

China Medical University

Jia Wang

China Medical University

Rui Zheng

China Medical University

\section{Dalu Wang}

Shengjing Hospital of China Medical University

Rui Yu

Shengjing Hospital of China Medical University

Beixing Liu ( $\sim$ bxliu@cmu.edu.cn)

China Medical University

Research

Keywords: NMU, ILC2 activation, NMUR1, RSV

Posted Date: October 12th, 2021

DOI: https://doi.org/10.21203/rs.3.rs-955142/v1

License: (c) (i) This work is licensed under a Creative Commons Attribution 4.0 International License. Read Full License 


\section{Abstract}

Background囚The activated group 2 innate lymphocytes (ILC2s) play a crucial role in respiratory syncytial virus (RSV)-induced airway inflammation by secreting large amount of type 2 cytokines. Although the classical activator IL-33 is the key factor for ILC2 activation, a regulatory effect of neurotransmitterneuromedin $\mathrm{U}(\mathrm{NMU})$ has also been reported. However, whether and how NMU can be elicited by RSV infection and regulate pulmonary ILC2 activation remains unclear.

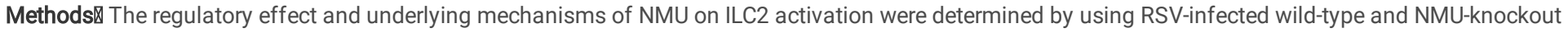
mice. The expression of NMU in the lungs and NMUR1 on ILC2s were measured by Real-time PCR and Western blot. Flow cytometry and ELISA were used to detect the proliferation and activation of ILC2s. The type of neurons secreting NMU and its possible secretion mechanism during RSV infection were also analyzed.

Results $₫$ Acute RSV infection induced the production of NMU in the lungs of mice and up-regulate the expression of NMUR1 on the pulmonary ILC2s. In vivo administration of NMU exacerbated RSV-induced airway inflammation by promoting the proliferation and activation of pulmonary ILC2s via NMUR1 pathway. In this process, PI3K, MEK and NFAT signal proteins might be involved. Furthermore, pulmonary neurons responded to the stimulation of RSV and secreted NMU in TLR4 and TLR7-dependent manners.

Conclusion冈Our data suggest that NMU is an ILC2 activator other than the classical activator, revealing a novel effect of neurotransmitter on RSV-induced airway inflammation.

\section{Introduction}

Respiratory syncytial virus (RSV) is a major pathogen causing fatal capillary bronchitis and pneumonia in infants, children, immunocompromised individuals and elderly populations[1]. Almost all infants and young children under 2 years of age have a history of RSV infection[2]. As a highly contagious respiratory disease, severe RSV infection can lead to asthma-like airway hyperresponsiveness (AHR) symptoms such as wheezing, cyanosis, dyspnea, and even induce acute asthma [3,4]. The Th2 dominant response caused by RSV infection may be related to these clinical symptoms[2, 5-7].

As an innate lymphoid cell type, group 2 innate lymphoid cells (ILC2s) have a powerful type 2 cytokine secretion capacity comparable to that of Th2 cells and are closely related to mucosal Th2 immune response[8]. ILC2s have been shown to be involved in airway inflammatory responses in human and murine models and can even induce airway inflammation independently of adaptive immunity[9]. Our previous experimental results have demonstrated that RSV infection can induce the proliferation and activation of pulmonary ILC2s, leading to the exacerbation of lung inflammation in the murine model. However, the mechanism has not been fully elucidated.

In recent years, the role of neuro-immune regulation in body homeostasis and diseases has attracted much attention. The respiratory tract is highly innervated by the autonomic nervous system derived from the parasympathetic nervous system. In addition to cytokines and chemokines, neurotransmitters such as neuropeptides and neurotrophic factors are also involved in the regulation of airway function[10]. Neuromedin U (NMU) is a group of smooth muscle stimulating peptides secreted by cholinergic neurons and belongs to the neuromedin family[11]. NMU is widely distributed in body tissues and organs and involved in a variety of body responses, ranging from appetite regulation, energy balance control, immune regulation to muscle contraction and tumor progression[11-13]. In immune regulation, NMU exerts pro-inflammatory effects in a neuron-dependent or independent manner, participating in the activation of immune cells and inducing the secretion of inflammatory cytokines. NMU-mediated inflammatory responses have been observed in animal models of helminth infection, sepsis, autoimmune arthritis and allergy[12]. There are two different binding receptors for NMU, neuromedin U receptor 1 (NMUR1) and neuromedin U receptor 2 (NMUR2), both of which belong to $\mathrm{G}$ protein-coupled receptor group A[14, 15]. NMUR1 was shown to be predominantly expressed in peripheral tissue organs, whereas NMUR2 was mainly expressed in the central nervous system[14]. NMU-NMUR1 signaling can regulate the immune response[16, 17]. But the effect of NMU on the biological activity of ILC2s in RSV-induced pulmonary infections and the role of NMU-NMUR1 signaling in this process is unclear.

In this study, by using BALB/c mice which were infected intranasally with RSV, the regulatory effect of NMU on the activation of pulmonary ILC2s as well as the underlying mechanism for NMU production in the lungs was investigated.

\section{Materials And Methods}

\section{Virus}

Human respiratory syncytial virus type A2 (RSV A2) was supplied initially by Dr. B. Wang, Center for Disease Control and Prevention, Shenyang, China. The virus was propagated in monolayers of HEp-2 cells (ATCC). The virus titer was expressed as a $50 \%$ tissue culture infectious dose (TCID50).

\section{Mice}

All animal experiments were approved and are in accordance with the guidelines of the Institutional Animal Care and Use Committee of China Medical University.

Wide-type mice on BALB/c background were purchased from Liaoning Changsheng Biotechnology Company (Benxi, China). NMU-knockout mice on C57BL/6J background were purchased from Cyagen Biotechnology Company (Suzhou, China). Mice were bred and maintained under specific pathogen-free condition at the laboratory animal center of China Medical University. All the experimental mice were female, 8 weeks old. 
Mice were anaesthetized with $1 \%$ pentobarbital sodium. For RSV infection model, mice were administered with $20 \mu$ l RSV suspension (containing approximately $1 \times 10^{7} \mathrm{TCID} 50$ ) via nasal mucosa, and experimental specimens were collected before infection and on day 1, 3, 5 after infection. In the NMU

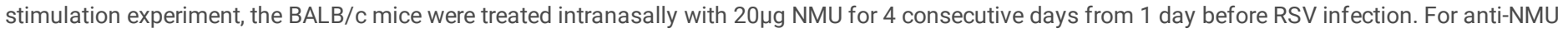
neutralization test, mice were injected intraperitoneally with anti-NMU-lgG $(10 \mathrm{mg} / \mathrm{kg}) 1$ day before RSV infection. All experimental specimens were collected on day 3 after RSV infection.

\section{Pulmonary single cell suspensions}

Mice were anesthetized with intraperitoneal injection of $1 \%$ pentobarbital sodium, heart perfusion was performed with sterile PBS. The alveolar lavage fluid was collected by alveolar flushing with $1 \mathrm{ml}$ PBS. The supernatant after centrifugation was used for ELISA to detect cytokine levels. Cell precipitation was used for HE staining. Lung tissue was removed and washed with cold PBS. The lung tissue was cut up into puree and RPMI-1640 with $10 \%$ FBS was used to

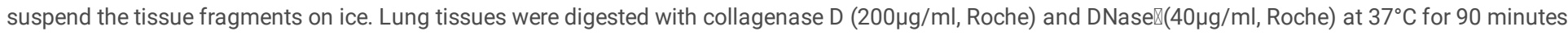
under agitation. After lysis of erythrocytes, cells were resuspended with PBS with $2 \%$ FBS and filtered through a $70 \mu \mathrm{m}$ cell strainer.

\section{Flow cytometry}

Intracellular cytokine staining was performed after incubation with PMA (25ng/ml, Sigma), lonomycin ( $1 \mu \mathrm{g} / \mathrm{ml} / \mathrm{L}$, Sigma) and Brefeldin A (10 $\mu \mathrm{g} / \mathrm{ml}$, Sigma) for 4 hours. Cell fixation was conducted according to the instructions of Cytofix/Cytoperm buffer set (BD bioscience). Ki67 as the proliferation indicator was stained per the staining protocol of manufacturer with 70\% Ethanol. After blocking the Fc-receptors with CD16/32 antibody (Biolegend), single cell suspensions were incubated with fluorescein-conjugated antibodies on ice for surface staining. Lineage antibody cocktail (eBioscience) components include DX5 (or NK1.1), CD3ع, CD4, CD5, CD8, CD11b, CD19, B220, Gr-1 and TCR6. Anti-CD45 (30-F11) and anti-Ki67(16A8) were purchased from Biolegend. Anti-IL-5 (TRFK5), anti-IL-13 (eBio13A) and anti-ST2 (DIH9) were obtained from eBioscience. Anti-NMUR1 was ordered from Bioss. Flow cytometry analysis were performed using LFRFortessa (BD Biosciences). The percentage of ILC2s was gated in CD $45^{+}$Lineage-ST2 $^{+}$cells. Data analysis was done by FlowJo_V10 software (Tristar).

\section{Quantitative Real-time PCR}

Total RNA was extracted from lung homogenates or sorted cells using TRIzol (Life Technologies). RNA concentration was determined by Nanodrop 2000 Spectrophotometer (Thermo Fisher). And then, PrimeScript ${ }^{\mathrm{TM}} \mathrm{RT}$ reagent kit (Takara) was applied to synthesize cDNA from isolated RNA. Quantitative Real-

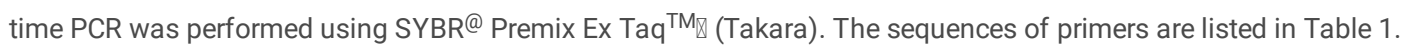

Table 1 Primers used for Real-time PCR

\begin{tabular}{lll} 
Gene & Forward $\left(5^{\prime}-3^{\prime}\right)$ & Reverse $\left(5^{\prime}-3^{\prime}\right)$ \\
\hline NMU & GCAGCTCGTCCCTCAACTG & CGTTGCGTGGCCTGAATAAA \\
\hline NMUR1 & CCTCGCTGTGTCCGATATGC & GCTGGAACGGGTAATTTTGCT \\
\hline IL-5 & GGCTTCCTGTCCCTACTCAT & TCCTCGCCACACTTCTCTTT \\
\hline IL-13 & AGCATGGTATGGAGTGTGGA & TTGCAATTGGAGATGTTGGT \\
\hline PI3K & CGAGAGTGTCGTCACAGTGTC & TGTTCGCTTCCACAAACACAG \\
\hline MEK1 & GTTGCTTTCAGGCCTCTCC & AGTGATGGGCTCTGCTTAGG \\
\hline NFAT & AGGCTCATTCCAGACACCG & GTCCTGCTCAGGTTTAGCCG \\
\hline TLR3 & GTGAGATACAACGTAGCTGACTG & TCCTGCATCCAAGATAGCAAGT \\
\hline TLR4 & GCCTTTCAGGGAATTAAGCTCC & GATCAACCGATGGACGTGTAAA \\
\hline TLR7 & ATGTGGACACGGAAGAGACAA & GGTAAGGGTAAGATTGGTGGTG \\
\hline -actin & GGTCATCACTATTGGCAACG & TCCATACCCAAGAAGGAAGG
\end{tabular}

Reactions were run using a 7500 Real-time PCR System (Applied Biosystems) under conventional amplification conditions. Results are normalized to $\beta$-actin and presented as fold mRNA expression $\left(2^{-\triangle \triangle C T}\right)$.

\section{Western blot}

Western blot was performed with standard methods. Cleaned and shredded lung tissues or cultured cell extracts were prepared in RIPA buffer supplemented with protease inhibitor. After protein quantification by BCA, equivalent amounts of total protein per sample were fractionated by SDS-PAGE and transferred onto PVDF membranes. The membranes were blocked with $5 \%$ BSA for 90 minutes at room temperature and incubated with the primary antibodies at $4{ }^{\circ} \mathrm{C}$ overnight. After washed with PBST, the membranes were incubated with corresponding secondary antibody for 1 hour at room temperature and detected by chemiluminescence. The rabbit anti-GAPDH (Affbiotech) or mouse anti- $\beta$-actin antibody (Absin) was used as an internal control. Densitometry was performed by Image $\mathrm{J}$ software. Protein levels were normalized to GAPDH or $\beta$-actin. 
Primary antibodies: mouse anti-NMU (Santa Cruz); rabbit anti-NMUR1 (EpiGentek); rabbit anti-pPI3K/PI3K (Affbiotech); rabbit anti-pMEK1/2/MEK1/2 (Affbiotech); rabbit anti-pNFAT2/NFAT2 (Affbiotech); rabbit anti-TLR4 (Affbiotech); rabbit anti-TLR7 (Affbiotech). Secondary antibodies: goat anti-mouse IgG HRP (Affbiotech); goat anti-rabbit IgG HRP (Affbiotech).

\section{ELISA}

The protein levels of IL-5 and IL-13 in the supernatants of cultured cells were measured by ELISA kits (Thermo Fisher) according to the manufacturer's instruction. The optical density at $450 \mathrm{~nm}$ was determined by Multimode Microplate Reader (Thermo Fisher).

\section{Cell sorting of ILC2s and CD4 ${ }^{+} \mathrm{T}$ cells}

RSV was administered to BALB/c mice intranasally, and pulmonary single cell suspensions were taken on day 3 after infection, unless stated otherwise. Lymphocytes were isolated according to the manufacturer's instruction of mouse viscera tissue lymphocyte isolation KIT (TBD, China). ILC2s defined as CD $45^{+}$Lineage ${ }^{-S T} 2^{+}$cells and CD $4^{+}$Tidentified as CD $45^{+}$Lineage ${ }^{+} \mathrm{CD} 4^{+}$cells were obtained using Beckman MoFlo Astrios EQ (Beckman Coulter Life Science). The average purity of sorted-purified cells was $>90 \%$.

\section{Isolation and culture of neurons}

Thoracic dorsal root ganglia (DRG) were dissected from neonatal mice of $1-3$ days old and digested in $0.25 \%$ trypsin for 30 minutes at $37^{\circ} \mathrm{C}$. Triple volume of DMEM/F12 (Gibco) supplemented with 10\% FBS, 1\% glutamine and 1\% streptomycin/penicillin was added to terminate digestion. DRG cell suspension was triturated with pasteur pipettes, followed by centrifugation. Then supernatant was discarded by centrifugation, and the cell pelltes was resuspended in neurobasal medium (Gibco) containing 2\% B27 (Gibco), 1\% glutamine, 0.5\% streptomycin/penicillin and 20ng/ml nerve growth factor (NGF) (Sigma). DRG neurons were cultured on $0.01 \%$ poly-L-Lysine pre-coated 12 -well culture plates in the culture medium described above for about a week to differentiate mature. DRG neurons were stimulated with RSV of increasing multiplicity of infection (MOI) for 60 minutes and RNA or protein was obtained at the indicated time for analysis.

For signal protein stimulation test, $1 \mathrm{ug} / \mathrm{ml}$ LPS (TLR4 agonist, Sigma) or 2ug/ml R837 (TLR7 agonist, MCE) was used to activate DRG neurons instead of RSV for 60 minutes. As for signal blocking analysis, we pretreated the DRG neurons with 200nM TAK-242 (TLR4 inhibitor, MCE) or 5ug/ml IRS661 (TLR7 antagonist, Invitrogen) for 15 minutes before RSV infection.

\section{In vitro stimulation}

Sorted ILC2s were cultured in RPMI-1640 (supplemented with 10\% FBS, $1 \%$ gulutamine and $1 \%$ streptomycin/penicillin) at $37^{\circ} \mathrm{C}$. ILC2s were cultured in the presence of $10 \mathrm{ng} / \mathrm{ml} \mathrm{IL-2}$ and $20 \mathrm{ng} / \mathrm{ml} \mathrm{IL-7} \mathrm{(Biolegend)} \mathrm{for} 24$ hours. Before use, ILC2s were gently washed to remove residual IL-2 and IL-7. ILC2s were cocultured with PBS or $100 \mathrm{ng} / \mathrm{ml}$ (unless stated otherwise) recombinant mouse NMU (Phoenix Pharmaceuticals) for 20 hours or indicated time intervals. After incubation, flow cytometry of cellular staining or RNA extraction was performed, and the cytokine levels in cultural supernatant were determined by ELISA.

$\mathrm{CD}^{+} \mathrm{T}$ cells were cultured in a $1 \mathrm{ug} / \mathrm{ml}$ anti-CD3 (Biolegend) pre-coated plate and in the presence of $1 \mathrm{ug} / \mathrm{ml}$ anti-CD28, 20ng/ml IL-2 and 50ng/ml IL-4 (Biolegend) for 3 days. As for stimulation, T cells were co-cultured with PBS or 100ng/ml NMU (Phoenix Pharmaceuticals) for 20 hours followed by RNA isolation.

\section{Cell signaling}

Purified ILC2s were cultured with 10\%FBS-RPMI-1640 with IL-2 and IL-7 for 24 hours as mentioned above. To analyze the effect of PI3K, MEK and NFAT, ILC2s were incubated with their respective inhibitors for 1 hour and then stimulated with $100 \mathrm{ng} / \mathrm{ml} \mathrm{NMU}$ for 12 hours before the analysis of cytokines and signal

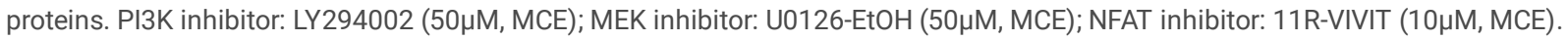

\section{HE staning}

The left lung tissue was fixed in $4 \%$ paraformaldehyde (PFA) and embedded in paraffin. The slices were cut into $4 \mu \mathrm{m}$ sections and stained with hematoxylin and eosin to detect inflammatory infiltrates. Photomicrographs were captured by biomicroscope (Zeiss).

\section{Immunofluorescence microscopy}

Samples from lungs were fixed with $4 \%$ PFA at $4^{\circ} \mathrm{C}$ overnight and then embedded in OCT to obtain frozen section. $10 \mu \mathrm{m}$ tissue slices were blocked and permeabilized with $0.5 \%$ Triton X-100 and 5\%BSA, and then incubated at $4^{\circ} \mathrm{C}$ overnight in wetting box with the following antibodies: Syrian hamster monoclonal anti-KLRG1 (2F1, Santa CruZ), mouse monoclonal anti-NMU (A-5, Santa CruZ) and rabbit anti-SNAP-25 (Abcam).

For cell staining, sorted ILC2s were stabilized for 24 hours on poly-L-Lysine pre-coated glass slides, and then cultured with or without NMU for 4 hours as described above. After stimulation, cells were fixed with 4\% PFA for 20 minutes at room temperature. Slides were permeabilized with $0.3 \%$ Triton X-100 for 20 minutes and blocked with 5\%BSA for 30 minutes at room temperature. Cells were stained with Syrian hamster monoclonal anti-KLRG1 (2F1, Santa CruZ) and rabbit anti-NMUR1 (EpiGentek) for 1 hour at room temperature.

Respective secondary antibodies were used subsequently at room temperature in the dark for 1 hour and nuclei was counterstained with DAPI (Abcam). Images were captured with confocal fluorescence microscopy (Olympus). Mean fluorescence intensity (MFI) was measured by ImageJ software. Secondary 
antibodies were as follows: AF488 goat anti-Syrian hamster, AF647 goat anti-rabbit, AF647 goat anti-mouse, AF647 goat anti-Syrian hamster, AF488 goat anti-rabbit.

\section{Customization of neutralizing antibodies}

Rabbit anti-NMU-IgG antibody was synthesized by ProbeGene (Jiangsu, China). The mouse NMU protein was synthesized (MSRAAGHRPGLSAGQLAAATASPLLSLLLLLACCADACKGVPISPQRLQPEQELQLWNEIHEACASFLSIDSRPQASVALRELCRIVMEISQKPQEQSEKDNTKRFLFHYSKTQ and New Zealand white rabbits were immunized with this protein for 4 times to obtain anti-NMU-IgG, which was purified by affinity chromatography.

Rabbit anti-NMUR1-IgG antibody was synthesized by ProbeGene (Jiangsu, China). The mouse NMUR1 peptide was synthesized (MTPPCLNCSIFPGALSPNASRSPLVCNISEFKWPYQPEDLNLTDEALRLKYLGPQQMKQFVPICVTYLLIFVVGTLGNGLTCTVILRNKTMRTPTNFYLFSLAVSDMLVLLVGL and New Zealand white rabbits were immunized with this peptide fragment for 4 times to obtain anti-NMUR1-IgG, which was purified by affinity chromatography.

\section{Statistical analysis}

Graphpad Prism 8 software was used to perform two-tailed and ordinary one-way or two-way ANOVA with Tukey's multiple comparisons test. Results are shown as mean \pm SEM. $\left({ }^{\star} P<0.05 ;{ }^{* \star} P<0.001 ;\right.$ ns, not significant $)$.

\section{Results}

\section{NMU is produced in the lungs of RSV-infected mice and adjacent to pulmonary ILC2s}

To confirm whether RSV infection can induce NMU production in the lungs, BALB/c mice were infected intranasally with RSV, and lung tissues were taken at day 1,3, 5 after infection. The levels of NMU were determined by Real-time PCR and Western-blot. The results showed that RSV infection significantly increased NMU production in the lungs, with the highest NMU levels at day 1 after infection (Figure 1A-B), suggesting that RSV infection could rapidly induce NMU secretion in the lung tissues.

Interestingly, RSV-induced NMU was found to be adjacent to ILC2s, which expressed the specific marker of KLRG1[18] (Figure 1C), leading us to speculate that NMU might have an effect on ILC2s.

\section{NMU facilitate pulmonary ILC2s to produce type 2 cytokines during RSV infection}

To determine the role of NMU in RSV-induced airway inflammation, BALB/c mice were injected NMU-neutralizing antibody intraperitoneally 1 day before RSV infection, we found that neutralizing NMU may attenuate NMU-exacerbated lung inflammation (Figure 2A), NMU-increased number of lymphocytes and eosinophils in BALF (Figure 2B), and NMU-enhanced secretion of the inflammatory cytokines of IL-5 and IL-13 in the lungs (Figure 2C). In contrast, intranasal administration of recombinant murine NMU to RSV infected mice in vivo aggravated the lung inflammatory infiltration, elevated lymphocytes and eosinophils in BALF, as well as the production of inflammatory cytokines. These data indicate that NMU does play a crucial role in mediating RSV induced airway inflammation especially via type 2 cytokines.

To clarify whether NMU can affect the ability of immune cells in the lungs during infection, BALB/c mice were intranasally administered with recombinant murine NMU for 4 consecutive days starting from day 1 before RSV infection. Pulmonary ILC2s and CD $4^{+}$T cells were sorted on day 3 after RSV infection and the relative expression of type 2 cytokines in these cells was detected by Real-time PCR. Results showed that NMU administration can significantly enhance the mRNA expressions of IL-5 and IL-13 in pulmonary ILC2s (Figure 2D). However, there was no significant change of inflammatory cytokines in CD $4^{+}$cells (Figure 2E), suggesting that NMU might have an activating effect on ILC2s, but not CD $4^{+}$cells. Indeed, when we neutralized the activity of NMU by intraperitoneal injection of NMU neutralizing antibody, the proliferation of pulmonary ILC2s as well as their ability to secret type 2 cytokines were reduced (Figure 2F-J).

Similar results were also observed by using RSV-infected NMU-knockout mice, in which the proliferation (Figure 3A) and activation (Figure 2B-C) of ILC2s were significantly decreased in the lungs of NMU-knockout mice as comparing with that in wild-type mice, demonstrating that NMU plays an indispensable role in the activation of ILC2s during RSV infection.

In vitro co-culture experiments further confirm the role of NMU on ILC2 activation. When cultured pulmonary ILC2s in the presence of NMU, the levels of type 2 cytokine IL-5 and IL-13 in pulmonary ILC2s were remarkably increased (Figure 4A). However, this phenomenon was not found in CD $4^{+} \mathrm{T}$ cells isolated from the lungs of RSV-infected mice (Figure 4B). Flow cytometry analysis showed that the proliferation and activation of ILC2s were elevated by incubation with the recombinant murine NMU in vitro (Figure 4C-E). Interestingly, combination of NMU and the classical ILC2 stimulator IL-33 may not boost NMU-mediated activation of ILC2s suggesting that the effect of NMU on ILC2 activation was not dependent on IL-33 (Figure 4F-G).

\section{NMU activates pulmonary ILC2s through NMUR1}

As a kind of neurotransmitter, NMU may exert its functions by binding to its receptor. To determine which cell type may express NMU receptor during RSV infection, we extracted RNA from pulmonary ILC2s, non-ILC2 lymphocytes and non-lymphoid cells of RSV-infected mice and performed Real-time PCR. Results showed that compared with other cell type, ILC2s were the main cells expressed high levels of NMUR1 (Figure 5A).Real-time PCR, Western blot and flow cytometry analysis also confirmed pulmonary ILC2s can express high levels of NMUR1 during RSV infection, particularly at day 1 after RSV infection (Figure 5B-D). 
In vitro stimulating pulmonary ILC2s with recombinant NMU can up-regulate NMUR1 expression on ILC2s (Figure 6A-B). However, blockade of NUMR1 by using NMUR1-blocking antibodies diminished NMU-induced activation of ILC2s and decrease their ability to produce type 2 cytokine IL-5 and IL-13 (Figure 6C-E). These data suggest that NMU regulates the activation of ILC2s through NMU-NMUR1 pathway during RSV infection.

\section{NMU regulates ILC2s via PI3K/NFAT and MEK/NFAT signals}

To explore the signal proteins involved in the process of activating ILC2s by NMU, we detected the signal proteins in ILC2s, which were isolated from the lungs of mice at day 3 after RSV infection. We found that stimulation with NMU may enhance the levels of p-PI3K, p-MEK and p-NFAT in ILC2s. However, when we pretreated ILC2s with selective signal protein inhibitors, the expression of IL-5 and IL-13 in pulmonary ILC2s were decreased (Figure 7A-F). Since inhibiting MEK (Figure 7G) or PI3K (Figure 7H) can reduce p-NFAT2 expression, suggesting that PI3K/NFAT and MEK/NFAT pathways play key roles on NMU-mediated activation of ILC2s during RSV infection.

\section{Neurons produce NMU in TLR4 and TLR7-dependent manners during RSV infection}

Immunofluorescence staining localized ILC2s (KLRG1) [18] and neurons (SNAP-25) in the lung tissue of RSV-infected BALB/c mice. The results revealed KLRG1 was in close proximity to SNAP-25 (Figure 8A), indicating that neurotransmitters derived from neurons may act directly on ILC2s. To clarify the source of NMU during RSV infection, the thoracic dorsal root ganglion neurons were extracted from neonatal mice and cultured to differentiate to mature in vitro. And then, the neurons were infected with RSV at different MOIs. The results showed that RSV infection increased the expression levels of NNU in the neurons, in which the MOl:10 was the optimal infectious dose (Figure 8B) and the best infection time was the $18^{\text {th }}$ hour after RSV infection (Figure 8C).

As pattern recognition receptors in the course of pathogen microbial infection[19, 20], Toll like receptors (TLRs) can recognize F protein and RNA of RSV[2123]. We further detected the relative expression of TLRs in RSV-infected neurons. The results showed that the expression levels of TLR4 and TLR7 in neuronal cells were significantly increased at hour 18 and 24 after RSV infection, while the expression of TLR3 was not significantly altered during RSV infection (Figure 8D). Notably, the expression of TLR4 and TLR7 in the neurons peaked at hour 18 after RSV infection (Figure 8E). TLR4 and TLR7 agonists increased the expression level of NMU in neuronal cells, whereas TLR4 and TLR7 antagonists inhibited NMU secretion by neurons (Figure 8F-G). Taken together, the experimental results suggest that RSV might stimulate lung neurons to secret NMU through the TLR4/TLR7 pathway.

\section{Discussion}

Previous studies have confirmed that RSV infection induces the proliferation and activation of ILC2s[24-26]. It is well established that the alarmins of IL-33, IL25, thymic stromal lymphopoietin (TSLP) and high mobility group box 1 (HMGB1) stimulates ILC2s to generate type 2 cytokines during the infection[26-28]. In recent years, the regulatory effects of neurotransmitters such as acetylcholine (Ach), NMU, neuromedin B (NMB), vasoactive intestinal polypeptide (VIP), and calcitonin gene-related peptide (CGRP) on immune cells has received increasing attention[16, 29-34]. Especially, NMU has been increasingly studied for its role in the activation of innate immune cells, eosinophils and mast cells in allergic or infectious diseases[17, 35-37]. NMU amplifies ILC2s-induced lung inflammation in asthma[35], and NMU alleviates helminth infection burden by activating ILC2s[16]. Yet, the mechanism of its regulatory effect on pulmonary ILC2s during RSV infection remains unclear. In the present study, we observed the accumulation of NMU around pulmonary ILC2s and the elevated expression of NMU in the acute phase during RSV infection. But there was not significant proliferation or activation of ILC2s in NMU-knockout mice as found in wide-type mice during the infection, suggesting that NMU plays a pivotal role in the regulation of ILC2s. Our current study demonstrates that NMU exacerbated the RSVinduced inflammatory and promoted the stimulation of ILC2s both in vivo and in vitro, whereas no significant difference was observed by the effect of NMU on $\mathrm{CD} 4^{+} \mathrm{T}$ cells. These data indicate that the pro-inflammatory effect of NMU on RSV infection is mainly via ILC2s, rather than CD $4^{+} \mathrm{T}$ cells, which is consistent with the results of NMU action on intestinal immune cells[38]. In addition to NMU, IL-33 is a potent strong stimulator of ILC2s[39], while RSV infection induces high expression of IL-33[40]. Applying the in vitro experiments, NMU was verified to activate ILC2s during RSV infection independent of IL-33. This is in accordance with the findings reported by Vânia Cardoso[16], whereas Heping Xu's group concluded that IL-33 in NMU plays a synergistic role in the activation of ILC2s[30].

It has been described that ILC2s specifically express NMUR1-a receptor of NMU by single-cell RNA sequence analysis[16, 41] and NMU-NMUR1 signaling regulates inflammatory responses[35, 36]. Here we found that NMUR1 was expressed in RSV-infected ILC2s rather than other type cells. Furthermore, neutralization of NMUR1 attenuated NMU-induced activation of ILC2s with concentration dependent in vitro, indicating that NMU-NMUR1 axis modulates the activation of RSV-infected ILC2s. The expression of NMUR1 on ILC2s was elevated in the acute phase of RSV infection. Similarly, intestinal ILC2s were found to show high NMUR1 expression during worm infection in mice[16]. However, as reported in in vitro experiments, NMU stimulation of ILC2s alone did not cause an increase in NMUR1 expression[35]. In this study, NMU stimulation caused higher expression of NMUR1 in RSV-infected ILC2s, which might be due to the different states between normal ILC2s and RSV-infected ILC2s, and NMU tended to induce the expression of NMUR1 in activated ILC2s rather than normal cells.

To further explore the modulation of RSV-infected inflammatory responses by NMU, we examined the signaling labels followed the activation of NMUR1 in ILC2s. Studies demonstrated that NFAT activity was required for the production of inflammatory cytokines [16, 42]. In the present study, we confirmed that besides NFAT, PI3K and MEK were also involved in the activation process in response to RSV infection, and especially via PI3K/NFAT and MEK/NFAT intracellular pathways by NMU-induced NMUR1 activation in RSV-infected ILC2s. The understanding of further molecular signaling cascades will lead to novel strategies for controlling inflammatory responses.

It has been reported that NMU is mainly secreted by cholinergic sensory neurons originating from DRG[34, 43, 44], while occasionally released by antigenpresenting cells (APCs) including monocytes, B cells, and dendritic cells[45]. Antonia Wallrapp et al confirmed that pulmonary NMU was derived from DRG neurons[35], while Vânia Cardoso and Christoph S.N. Klose used enteric neurons isolated and differentiated from the intestine of embryos[16, 38]. In the 
current study, we found RSV increased the expression level of NMU in the thoracic DRG neurons in vitro, indicating that pulmonary NMU is originated from the DRG neuronal cells. Worthwhile, IL-33[16] and IL-13[35] have been reported to induce NMU secretion, meanwhile RSV infection causes elevated IL-33 and increased IL-13 secretion in lung[24]. Thus, we conclude that the release of NMU in RSV-infected mice might be the result of a combination of effects. However, the mechanism by which neuronal cells respond to the stimulus and then secrete neurotransmitters is not well understood. The role of TLRs in the immunity against pathogen invasion has been established[19, 46, 47]. Both neuronal cells[48-50]and DRG[51-53] express TLRs. RSV is a single-stranded negative-stranded RNA virus, while TLR3 and TLR7 can recognize double-stranded RNA and single-stranded RNA during RSV replication, respectively[21, 23]. TLR4 may bind to the F protein on the surface of RSV[22]. Accordingly, as pattern recognition receptors, TLRs are of interest for their roles on NMU secretion by neuronal cells. Our further investigation with the agonists and antagonists of the signal proteins found that RSV induced neurons to secrete NMU through TLR4 and TLR7 pathway. Finally, after TLRs detect RSV, which cascade reactions triggered, which transcription factors activated, and eventually causing the secretion of NMU, remains to further study in future.

\section{Conclusion}

Collectively, these results reveal a previously unrecognized role of the interaction between nervous system and immune system at respiratory mucosal barrier during RSV infection. RSV induces neuronal secretion of NMU through multiple ways, and NMU exacerbates the type 2 inflammatory response by regulating the proliferation and activation of ILC2s. In pulmonary diseases caused by pathogenic infections or other irritants, neuromodulation may rapidly aggravate the inflammatory and allergy-like responses induced by type 2 cytokines through ILC2s, which opens a new chapter in our understanding of the onset and progression of respiratory diseases.

\section{Abbreviations}

ILC2: group 2 innate lymphocytes

RSV: respiratory syncytial virus

NMU: neuromedin U

NMUR1: neuromedin U receptor 1

NMUR2: neuromedin U receptor 2

AHR: airway hyperresponsiveness

TCID50: 50\% tissue culture infectious dose

DRG: dorsal root ganglia

MOI: multiplicity of infection

MFI: mean fluorescence intensity

TLR: toll like receptors

TSLP: thymic stromal lymphopoietin

HMGB1: high mobility group box 1

Ach: acetylcholine

NMB: neuromedin B

VIP: vasoactive intestinal polypeptide

CGRP: calcitonin gene-related peptide

APCs: antigen-presenting cells

WT: wide type

\section{Declarations}

\section{Ethics approval}

All procedures involving animals were conducted in accordance with the guidelines of the Institutional Animal Care and Use Committee of China Medical University.

\section{Consent for publication}


Not applicable.

\section{Availability of data and materials}

All data generated or analyzed during this work are available upon request.

\section{Competing interests}

The authors declare that they have no competing interests.

\section{Funding}

This work is supported by the foundation of the Department of Science and Technology of Liaoning province.

\section{Authors' contributions}

LW: Methodology, Data analysis, Writing - original draft; WS: Formal analysis, Investigation; WJ and ZR: Animal experiment; WD and YR: Cell culture; LB: Conceptualization, Funding acquisition, Supervision, Writing - review \& editing.

All the authors read and approved the final manuscript.

\section{Acknowledgements}

Not applicable

Author information

Affiliations

Department of Pathogenic Biology, School of Basic Medical Science, China Medical University, Shenyang 110122, China

Weiwei Liu, Si Wang, Jia Wang, Rui Zheng, Beixing Liu

Department of anesthesiology, The First Hospital of China Medical University, Shenyang 110001, China.

Weiwei Liu

Department of General Surgery, Shengjing Hospital of China Medical University, Shenyang, China

Dalu Wang

\section{Department of Nephrology, Shengjing Hospital of China Medical University, Shenyang, China}

Rui Yu

\section{Corresponding author}

Correspondence to Beixing Liu.

\section{Acknowledgements}

Not applicable.

\section{References}

1. Zanone SM, Krause LK, Madhi SA, Bassat Q, Jha P, Simoes EA, et al. Challenges in estimating RSV-associated mortality rates. Lancet Respir Med. 2016;4(5):345-7. http://dx.doi.org/10.1016/S2213-2600(16)30042-X.

2. Everard ML. The relationship between respiratory syncytial virus infections and the development of wheezing and asthma in children. Curr Opin Allergy Clin Immunol. 2006;6(1):56-61. http://dx.doi.org/10.1097/01.all.0000200506.62048.06.

3. Castro M, Schweiger T, Yin-DeClue H, Ramkumar TP, Christie $\mathrm{C}$, Zheng J, et al. Cytokine response after severe respiratory syncytial virus bronchiolitis in early life. J Allergy Clin Immunol. 2008;122(4):726-33. e3.http://dx.doi.org/10.1016/j.jaci.2008.07.010.

4. Corren J. Role of interleukin-13 in asthma. Curr Allergy Asthma Rep. 2013;13(5):415-20. .http://dx.doi.org/10.1007/s11882-013-0373-9.

5. Bacharier LB, Cohen R, Schweiger T, Yin-Declue H, Christie C, Zheng J, et al. Determinants of asthma after severe respiratory syncytial virus bronchiolitis. J Allergy Clin Immunol. 2012;130(1):91-100. e3.http://dx.doi.org/10.1016/j.jaci.2012.02.010.

6. Lotz MT, Peebles RS Jr. Mechanisms of respiratory syncytial virus modulation of airway immune responses. Curr Allergy Asthma Rep. 2012;12(5):380-7. http://dx.doi.org/10.1007/s11882-012-0278-z.

7. Lambert L, Sagfors AM, Openshaw PJ, Culley FJ. Immunity to RSV in Early-Life. Front Immunol. 2014;5:466. http://dx.doi.org/10.3389/fimmu.2014.00466. 
8. Klose CS, Artis D. Innate lymphoid cells as regulators of immunity, inflammation and tissue homeostasis. Nat Immunol. 2016;17(7):765-74. http://dx.doi.org/10.1038/ni.3489.

9. Price AE, Liang HE, Sullivan BM, Reinhardt RL, Eisley CJ, Erle DJ, et al. Systemically dispersed innate IL-13-expressing cells in type 2 immunity. Proc Natl Acad Sci U S A. 2010;107(25):11489-94. http://dx.doi.org/10.1073/pnas.1003988107.

10. Ordovas-Montanes J, Rakoff-Nahoum S, Huang S, Riol-Blanco L, Barreiro O, von Andrian UH. The Regulation of Immunological Processes by Peripheral Neurons in Homeostasis and Disease. Trends Immunol. 2015;36(10):578-604. .http://dx.doi.org/10.1016/j.it.2015.08.007.

11. Martinez VG, O'Driscoll L. Neuromedin U. a multifunctional neuropeptide with pleiotropic roles. Clin Chem. 2015;61(3):471-82. http://dx.doi.org/10.1373/clinchem.2014.231753.

12. Ye Y, Liang Z, Xue L. Neuromedin U. potential roles in immunity and inflammation. Immunology. 2021;162(1):17-29. http://dx.doi.org/10.1111/imm.13257.

13. Przygodzka P, Soboska K, Sochacka E, Boncela J. Neuromedin U. A Small Peptide in the Big World of Cancer. Cancers (Basel). 2019;11(9).http://dx.doi.org/10.3390/cancers11091312.

14. Hedrick JA, Morse K, Shan L, Qiao X, Pang L, Wang S, et al. Identification of a human gastrointestinal tract and immune system receptor for the peptide neuromedin U. Mol Pharmacol. 2000;58(4):870-5. .http://dx.doi.org/10.1124/mol.58.4.870.

15. Minamino N, Sudoh T, Kangawa K, Matsuo H. Neuromedins: novel smooth-muscle stimulating peptides identified in porcine spinal cord. Peptides. 1985;6(Suppl 3):245-8.

16. Cardoso V, Chesne J, Ribeiro H, Garcia-Cassani B, Carvalho T, Bouchery T, et al. Neuronal regulation of type 2 innate lymphoid cells via neuromedin U. Nature. 2017;549(7671):277-81. http://dx.doi.org/10.1038/nature23469.

17. Veiga-Fernandes H, Pachnis V. Neuroimmune regulation during intestinal development and homeostasis. Nat Immunol. 2017;18(2):116-22. http://dx.doi.org/10.1038/ni.3634.

18. Hoyler T, Klose CS, Souabni A, Turqueti-Neves A, Pfeifer D, Rawlins EL, et al. The transcription factor GATA-3 controls cell fate and maintenance of type 2 innate lymphoid cells. Immunity. 2012;37(4):634-48. .http://dx.doi.org/10.1016/j.immuni.2012.06.020.

19. Kawai T, Akira S. TLR signaling. Cell Death Differ. 2006;13(5):816-25. .http://dx.doi.org/10.1038/sj.cdd.4401850.

20. Takeuchi O, Akira S. Pattern recognition receptors and inflammation. Cell. 2010;140(6):805-20. http://dx.doi.org/10.1016/j.cell.2010.01.022.

21. Oshiumi H, Okamoto M, Fujii K, Kawanishi T, Matsumoto M, Koike S, et al. The TLR3/TICAM-1 pathway is mandatory for innate immune responses to poliovirus infection. J Immunol. 2011;187(10):5320-7. http://dx.doi.org/10.4049/jimmunol.1101503.

22. Yuan X, Hu T, He H, Qiu H, Wu X, Chen J, et al. Respiratory syncytial virus prolifically infects N2a neuronal cells, leading to TLR4 and nucleolin protein modulations and RSV F protein co-localization with TLR4 and nucleolin. J Biomed Sci. 2018;25(1):13. http://dx.doi.org/10.1186/s12929-018-0416-6.

23. Lund JM, Alexopoulou L, Sato A, Karow M, Adams NC, Gale NW, et al. Recognition of single-stranded RNA viruses by Toll-like receptor 7. Proc Natl Acad Sci U S A. 2004;101(15):5598-603. http://dx.doi.org/10.1073/pnas.0400937101.

24. Stier MT, Bloodworth MH, Toki S, Newcomb DC, Goleniewska K, Boyd KL, et al. Respiratory syncytial virus infection activates IL-13-producing group 2 innate lymphoid cells through thymic stromal lymphopoietin. J Allergy Clin Immunol. 2016;138(3).http://dx.doi.org/10.1016/j.jaci.2016.01.050.

25. Fonseca W, Malinczak C-A, Schuler CF, Best SKK, Rasky AJ, Morris SB, et al. Uric acid pathway activation during respiratory virus infection promotes Th2 immune response via innate cytokine production and ILC2 accumulation. Mucosal Immunol. 2020;13(4):691-701. .http://dx.doi.org/10.1038/s41385020-0264-z.

26. Norlander AE, Peebles RS. Innate Type 2 Responses to Respiratory Syncytial Virus Infection. Viruses. 2020;12(5).http://dx.doi.org/10.3390/v12050521.

27. Saravia J, You D, Shrestha B, Jaligama S, Siefker D, Lee GI, et al. Respiratory Syncytial Virus Disease Is Mediated by Age-Variable IL-33. PLoS Pathog. 2015;11(10):e1005217. .http://dx.doi.org/10.1371/journal.ppat.1005217.

28. Stier MT, Bloodworth MH, Toki S, Newcomb DC, Goleniewska K, Boyd KL, et al. Respiratory syncytial virus infection activates IL-13-producing group 2 innate lymphoid cells through thymic stromal lymphopoietin. J Allergy Clin Immunol. 2016;138(3):814-24. e11.http://dx.doi.org/10.1016/j.jaci.2016.01.050.

29. Sui P, Wiesner DL, Xu J, Zhang Y, Lee J, Van Dyken S, et al. Pulmonary neuroendocrine cells amplify allergic asthma responses. Science 2018 (New York, N.Y.). ;360(6393).http://dx.doi.org/10.1126/science.aan8546.

30. Xu H, Ding J, Porter CBM, Wallrapp A, Tabaka M, Ma S, et al. Transcriptional Atlas of Intestinal Immune Cells Reveals that Neuropeptide alpha-CGRP Modulates Group 2 Innate Lymphoid Cell Responses. Immunity. 2019;51(4):696-708. e9.http://dx.doi.org/10.1016/j.immuni.2019.09.004.

31. Audrit KJ, Delventhal L, Aydin O, Nassenstein C. The nervous system of airways and its remodeling in inflammatory lung diseases. Cell Tissue Res. 2017;367(3):571-90. http://dx.doi.org/10.1007/s00441-016-2559-7.

32. Galle-Treger L, Suzuki Y, Patel N, Sankaranarayanan I, Aron JL, Maazi H, et al. Nicotinic acetylcholine receptor agonist attenuates ILC2-dependent airway hyperreactivity. Nat Commun. 2016;7:13202. http://dx.doi.org/10.1038/ncomms13202.

33. Inclan-Rico JM, Ponessa JJ, Valero-Pacheco N, Hernandez CM, Sy CB, Lemenze AD, et al. Basophils prime group 2 innate lymphoid cells for neuropeptidemediated inhibition. Nature immunology. 2020;21(10):1181-93. .http://dx.doi.org/10.1038/s41590-020-0753-y.

34. Chen W, Shu Q, Fan J. Neural Regulation of Interactions Between Group 2 Innate Lymphoid Cells and Pulmonary Immune Cells. Front Immunol. 2020;11:576929. http://dx.doi.org/10.3389/fimmu.2020.576929.

35. Wallrapp A, Riesenfeld SJ, Burkett PR, Abdulnour RE, Nyman J, Dionne D, et al. The neuropeptide NMU amplifies ILC2-driven allergic lung inflammation. Nature. 2017;549(7672):351-6. .http://dx.doi.org/10.1038/nature24029.

Page $9 / 18$ 
36. Moriyama M, Fukuyama S, Inoue H, Matsumoto T, Sato T, Tanaka K, et al. The neuropeptide neuromedin U activates eosinophils and is involved in allergen-induced eosinophilia. Am J Physiol Lung Cell Mol Physiol. 2006;290(5):L971-7. http://dx.doi.org/10.1152/ajplung.00345.2005.

37. Moriyama M, Sato T, Inoue H, Fukuyama S, Teranishi H, Kangawa K, et al. The neuropeptide neuromedin U promotes inflammation by direct activation of mast cells. J Exp Med. 2005;202(2):217-24. http://dx.doi.org/10.1084/jem.20050248.

38. Klose CSN, Mahlakoiv T, Moeller JB, Rankin LC, Flamar AL, Kabata H, et al. The neuropeptide neuromedin U stimulates innate lymphoid cells and type 2 inflammation. Nature. 2017;549(7671):282-6. http://dx.doi.org/10.1038/nature23676.

39. Kabata H, Moro K, Koyasu S. The group 2 innate lymphoid cell (ILC2) regulatory network and its underlying mechanisms. Immunol Rev. 2018;286(1):3752. http://dx.doi.org/10.1111/imr.12706.

40. Qi F, Bai S, Wang D, Xu L, Hu H, Zeng S, et al. Macrophages produce IL-33 by activating MAPK signaling pathway during RSV infection. Mol Immunol. 2017;87:284-92. .http://dx.doi.org/10.1016/j.molimm.2017.05.008.

41. Bray NL, Pimentel H, Melsted P, Pachter L. Near-optimal probabilistic RNA-seq quantification. Nat Biotechnol. 2016;34(5):525-7. http://dx.doi.org/10.1038/nbt.3519.

42. Hermann-Kleiter N, Baier G. NFAT pulls the strings during CD4+ T helper cell effector functions. Blood. 2010;115(15):2989-97. http://dx.doi.org/10.1182/blood-2009-10-233585.

43. Moriyama M, Furue H, Katafuchi T, Teranishi H, Sato T, Kano T, et al. Presynaptic modulation by neuromedin $\mathrm{U}$ of sensory synaptic transmission in rat spinal dorsal horn neurones. J Physiol. 2004;559(Pt 3):707-13.

44. Domin J, Ghatei MA, Chohan P, Bloom SR. Neuromedin U-a study of its distribution in the rat. Peptides. 1987;8(5):779-84.

45. Hedrick JA, Morse K, Shan L, Qiao X, Pang L, Wang S, et al. Identification of a human gastrointestinal tract and immune system receptor for the peptide neuromedin U. Mol Pharmacol. 2000;58(4):870-5.

46. Kawai T, Akira S. The role of pattern-recognition receptors in innate immunity: update on Toll-like receptors. Nature immunology. 2010;11(5):373-84. http://dx.doi.org/10.1038/ni.1863.

47. Fitzgerald KA, Kagan JC. Toll-like Receptors and the Control of Immunity. Cell. 2020;180(6):1044-66. .http://dx.doi.org/10.1016/j.cell.2020.02.041.

48. Xu ZZ, Kim YH, Bang S, Zhang Y, Berta T, Wang F, et al. Inhibition of mechanical allodynia in neuropathic pain by TLR5-mediated A-fiber blockade. Nat Med. 2015;21(11):1326-31. .http://dx.doi.org/10.1038/nm.3978.

49. Liu T, Berta T, Xu ZZ, Park CK, Zhang L, Lu N, et al. TLR3 deficiency impairs spinal cord synaptic transmission, central sensitization, and pruritus in mice. J Clin Invest. 2012;122(6):2195-207. http://dx.doi.org/10.1172/JCl45414.

50. Kim D, Kim MA, Cho IH, Kim MS, Lee S, Jo EK, et al. A critical role of toll-like receptor 2 in nerve injury-induced spinal cord glial cell activation and pain hypersensitivity. J Biol Chem. 2007;282(20):14975-83. http://dx.doi.org/10.1074/jbc.M607277200.

51. Zhang ZJ, Guo JS, Li SS, Wu XB, Cao DL, Jiang BC, et al. TLR8 and its endogenous ligand miR-21 contribute to neuropathic pain in murine DRG. J Exp Med. 2018;215(12):3019-37. http://dx.doi.org/10.1084/jem.20180800.

52. Huang J, Gandini MA, Chen L, M'Dahoma S, Stemkowski PL, Chung H, et al. Hyperactivity of Innate Immunity Triggers Pain via TLR2-IL-33-Mediated Neuroimmune Crosstalk. Cell Rep. 2020;33(1):108233. http://dx.doi.org/10.1016/j.celrep.2020.108233.

53. Wang Z, Liu F, Wei M, Qiu Y, Ma C, Shen L, et al. Chronic constriction injury-induced microRNA-146a-5p alleviates neuropathic pain through suppression of IRAK1/TRAF6 signaling pathway. J Neuroinflammation. 2018;15(1):179. http://dx.doi.org/10.1186/s12974-018-1215-4.

\section{Figures}


A

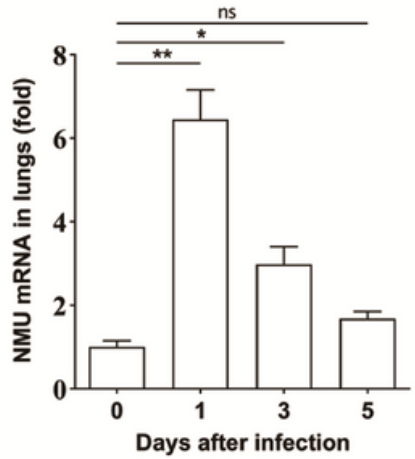

B
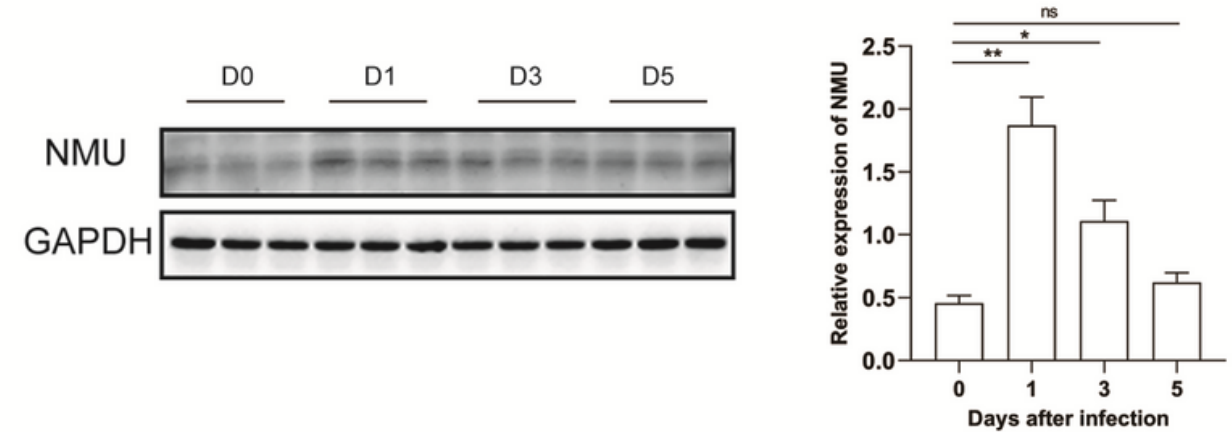

C
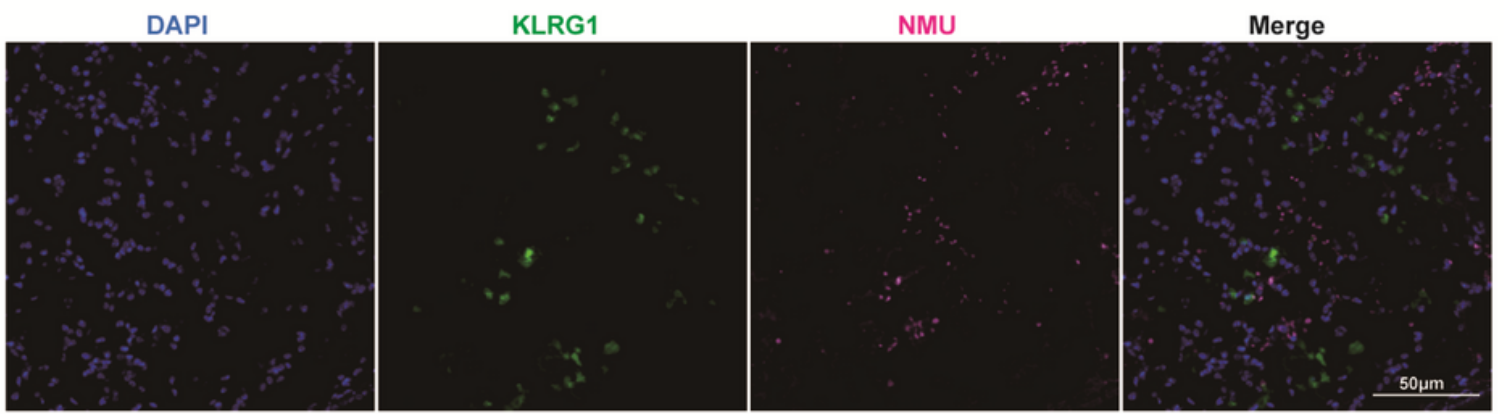

\section{Figure 1}

RSV infection induces NMU expression in the lungs of mice. A-B Expression of NMU was determined by Real-time PCR (A) and Western blot (B) in RSVinfected lung tissues at the indicated time points. $n=3$. C Immunofluorescent staining of the production of NMU in the lungs of mice on day 1 after infection. Bar $=50 \mu \mathrm{m}$. Data are representative of three individual experiments, error bars represent $S E M ; * P<0.05, * * P<0.001$ by one-way ANOVA. 

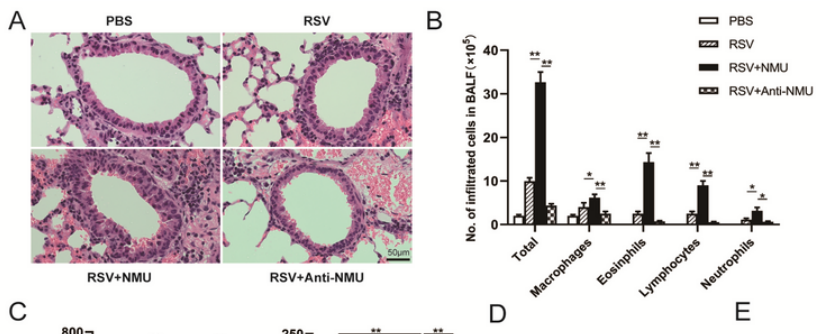

$\mathrm{C}$
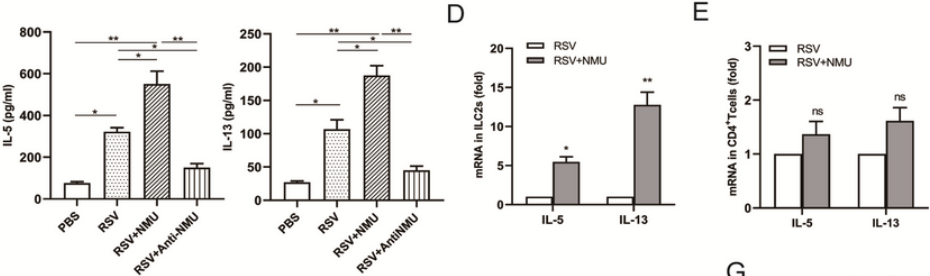

F

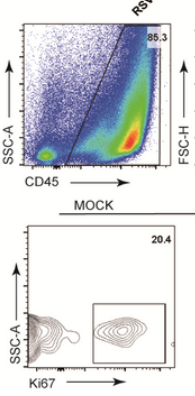

I
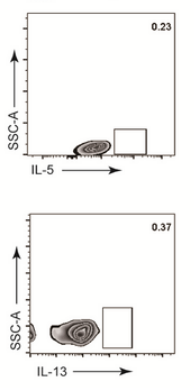
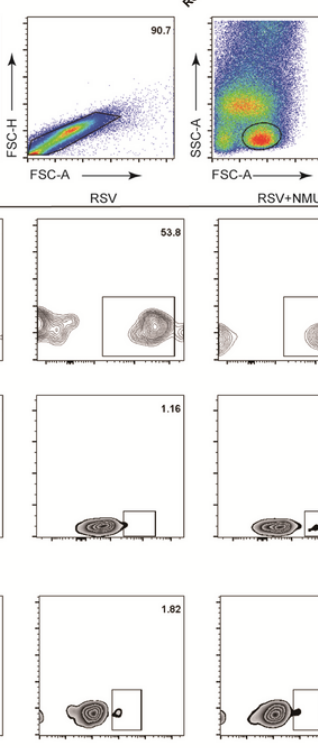
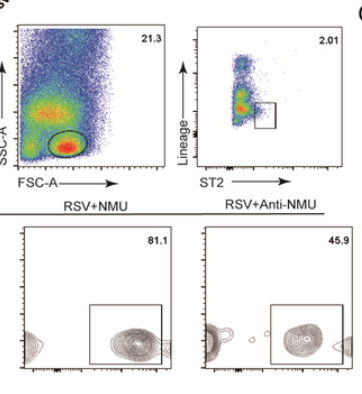

G
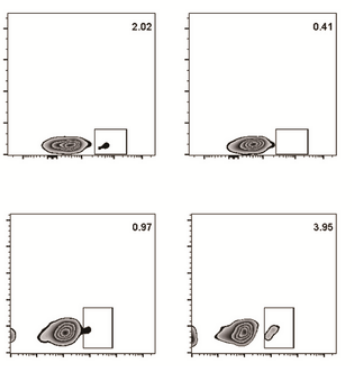

\section{Figure 2}

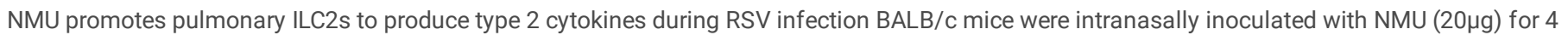

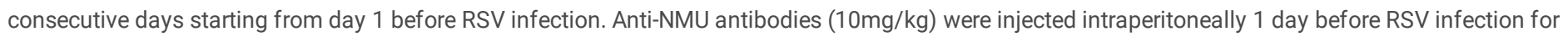

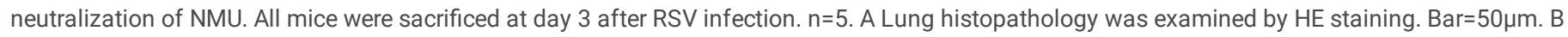

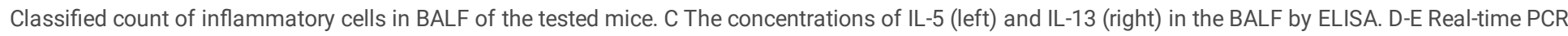

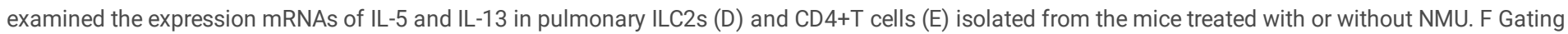

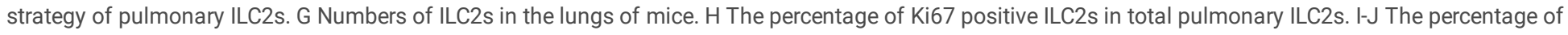

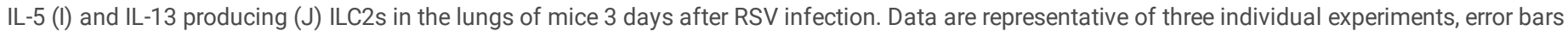
represent $S E M ;{ }^{*} P<0.05,{ }^{*} \mathrm{P}<0.001$ by one-way ANOVA $(C, G-J)$ or two-way ANOVA $(B, D, E)$. 
A

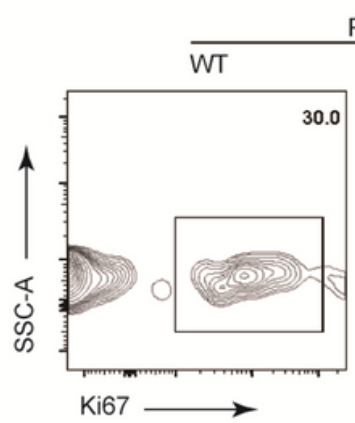

PBS

B
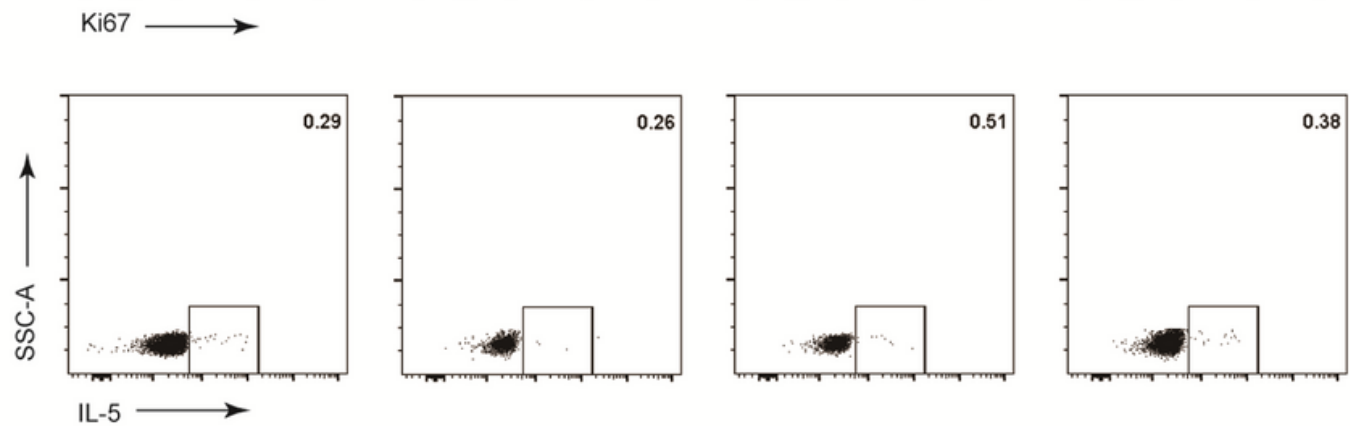

C

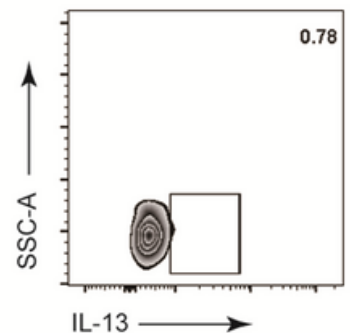

RSV
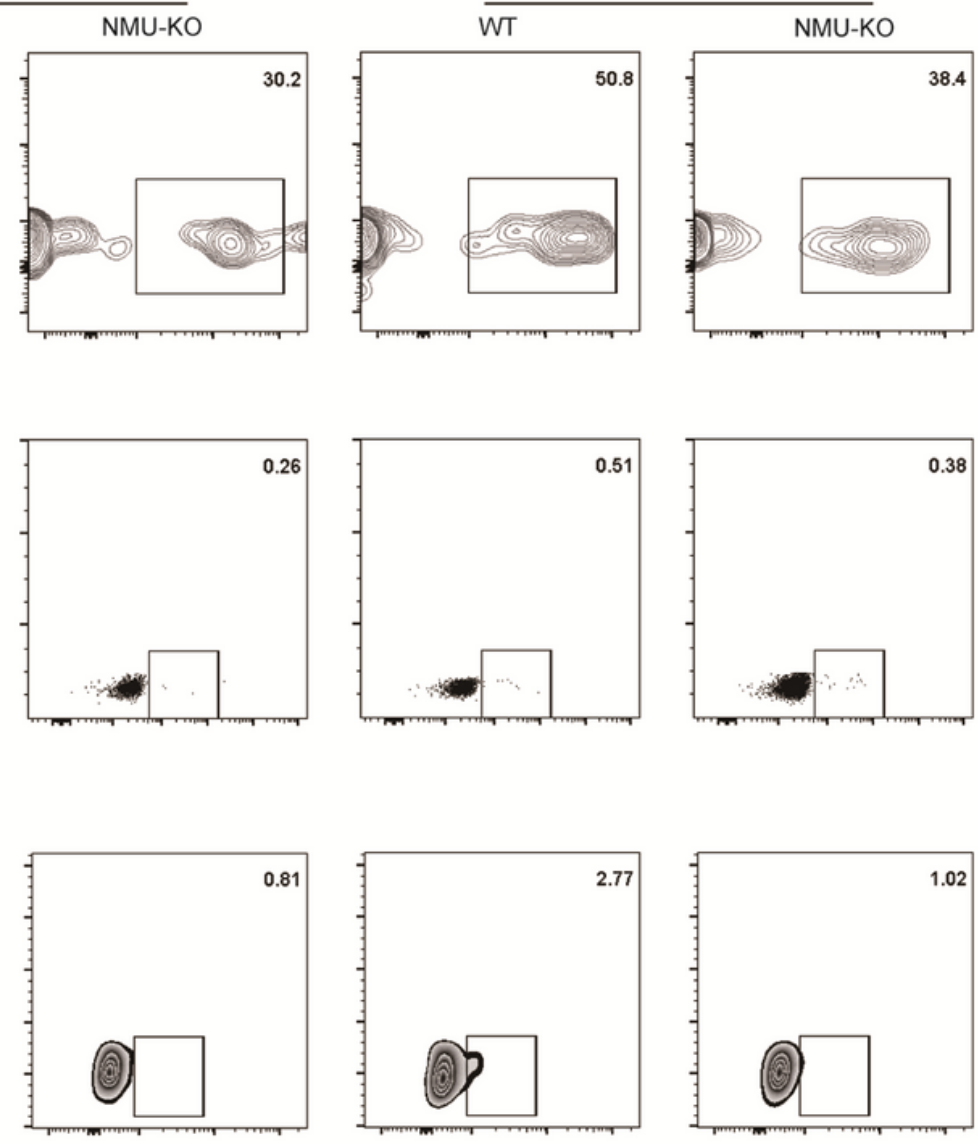
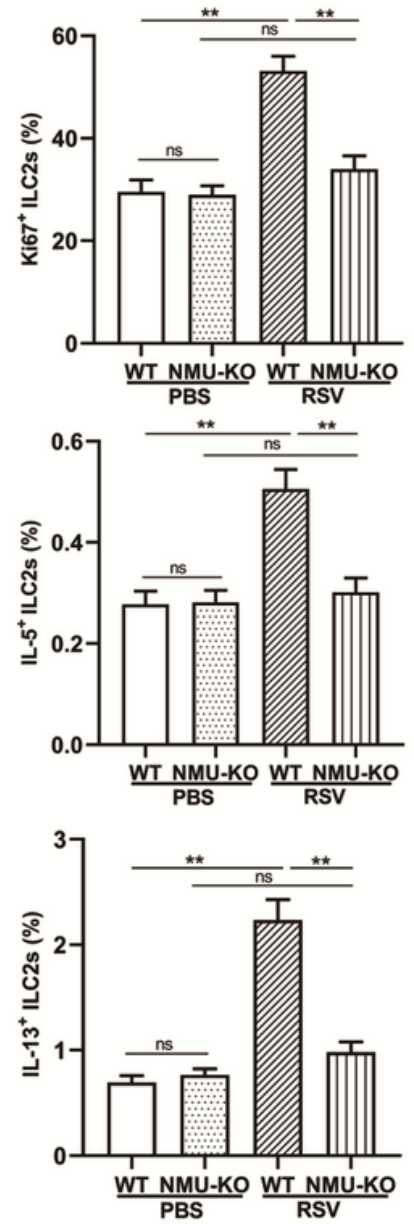

Figure 3

Knockout of NMU decreases the activation of pulmonary ILC2s during RSV infection. Flow cytometry analysis of wide-type and NMU-knockout mice that were intranasally inoculated with PBS or RSV. $n=5$. A The percentage of Ki67 positive ILC2s in the lungs of mice. B-C The percentage of IL-5 (B) or IL-13 (C) producing ILC2s in the lungs of mice. Data are representative of three individual experiments, error bars represent $S E M ; * P<0.05$, ${ }^{\star *} P<0.001$ by one-way $A N O V A$, ns not significant. 
A

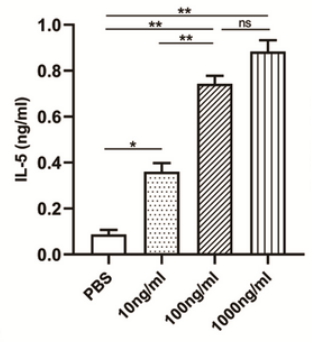

C

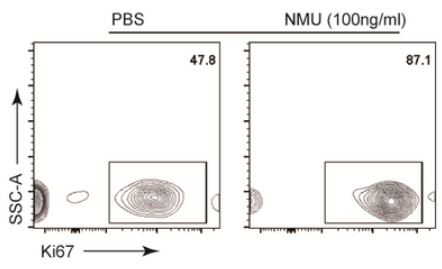

D

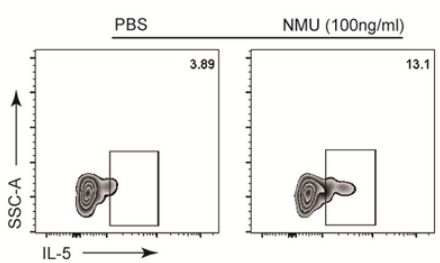

E

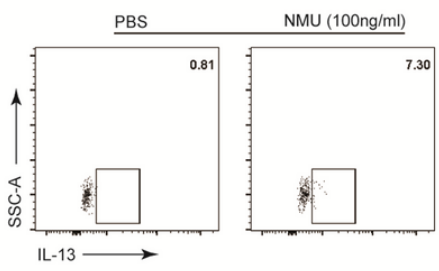

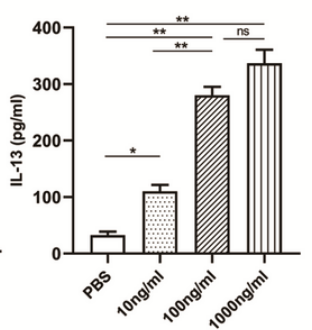
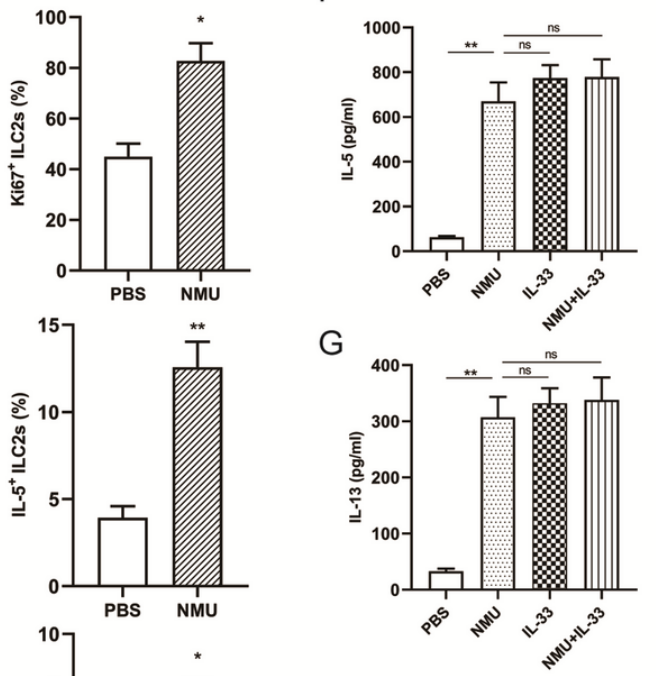

F
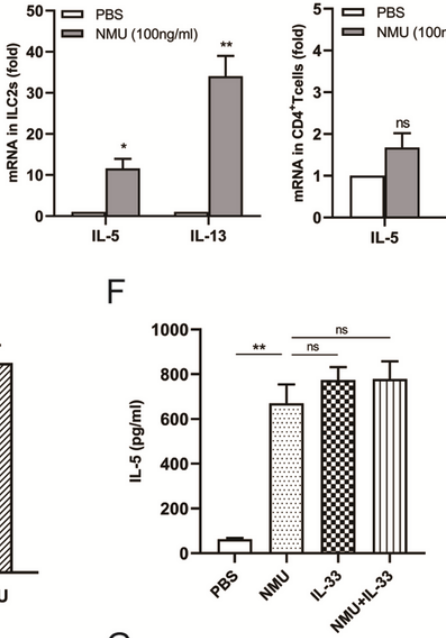

*
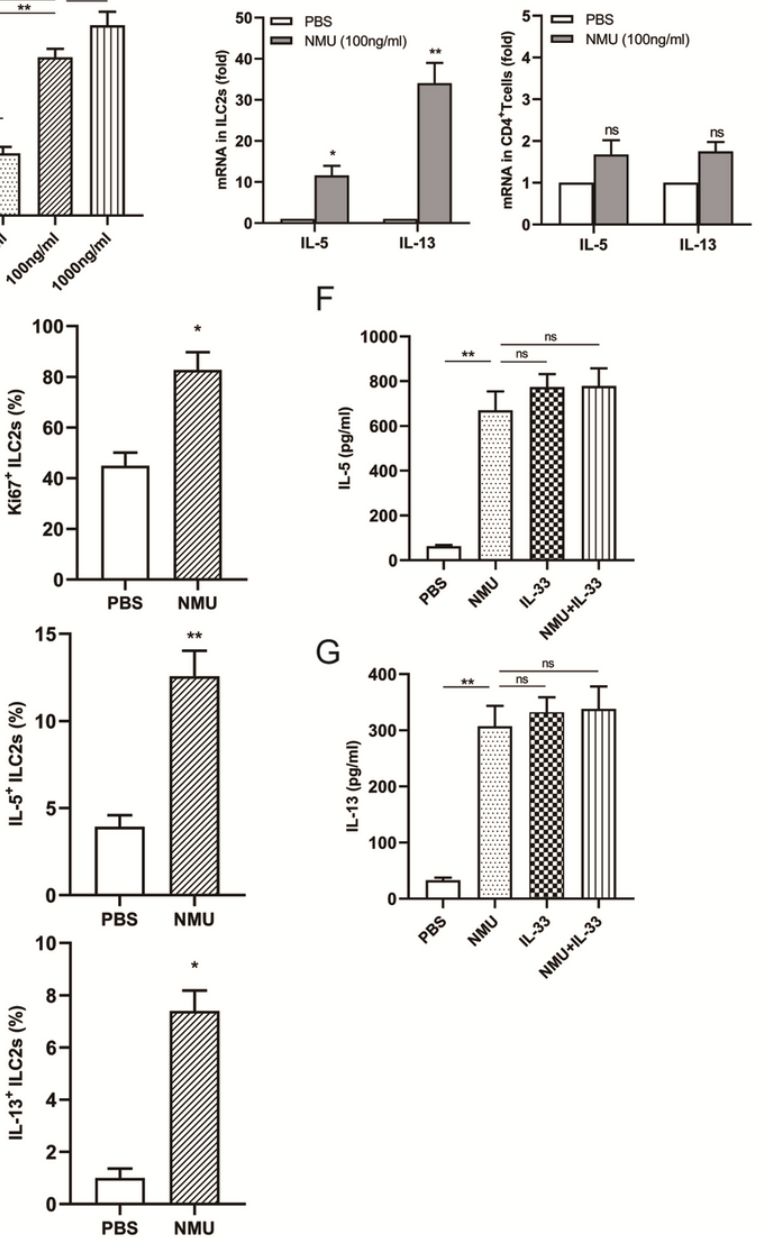

Figure 4

NMU induces ILC2 activation independent upon IL-33. ILC2s were sorted from the lungs of mice on day 3 after RSV infection and co-cultured in vitro with or without NMU for 20 hours. A Concentration of IL-5 (left) or IL-13 (right) in the culture supernatant of ILC2s was determined by ELISA. n=3. B The expressions of IL-5 and IL-13 in the cultured cells were detected by Real-time PCR. $n=4$. C Flow cytometric analysis of Ki67 positive ILC2s after NMU stimulation. $n=3$. D-E Flow cytometric analysis of IL-5 (D) or IL-13 (E) producing ILC2s. n=3. F-G Sorted ILC2s were cultured in the presence of NMU, IL-33 or both for 20 hours. The concentration of IL-5 (F) or IL-13 (G) in the culture supernatant was determined by ELISA. $n=3$. Data are representative of at least two individual experiments, error bars represent SEM; ${ }^{*} \mathrm{P}<0.05,{ }^{*} \mathrm{P}<0.001$ one-way ANOVA $(\mathrm{A}, \mathrm{F})$ or two-way ANOVA (B), or two-tailed t-test (C-E), ns not significant. 


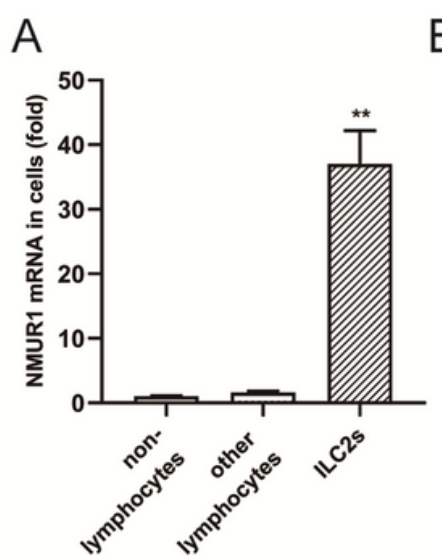

B

C

D

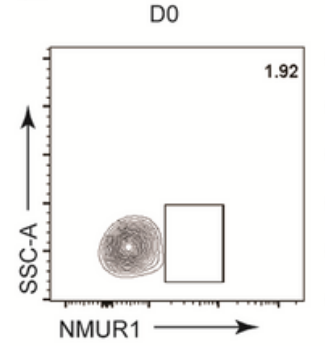

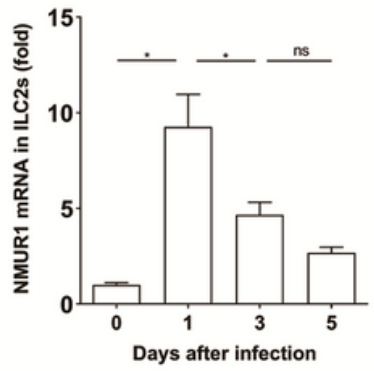

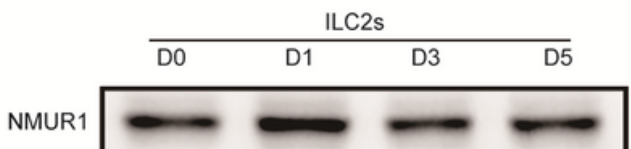

$\beta$-actin

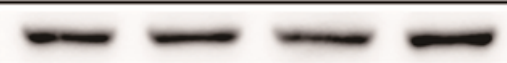

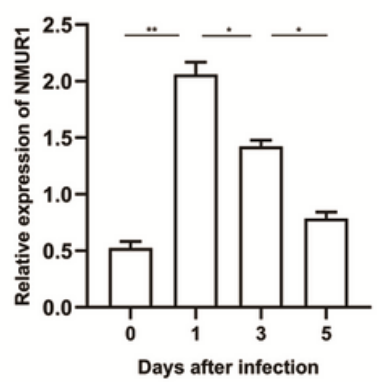

D1

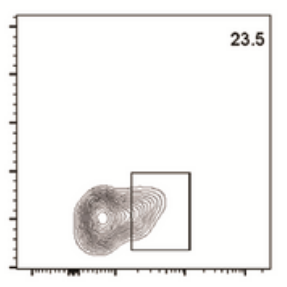

D3

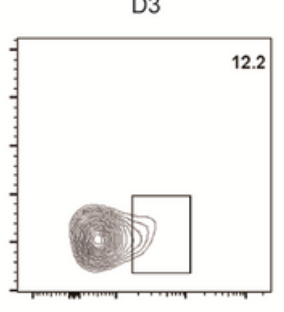

D5

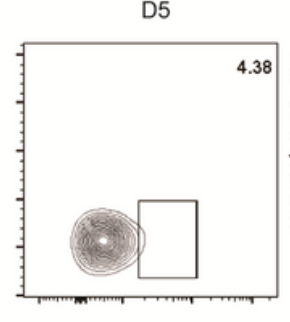

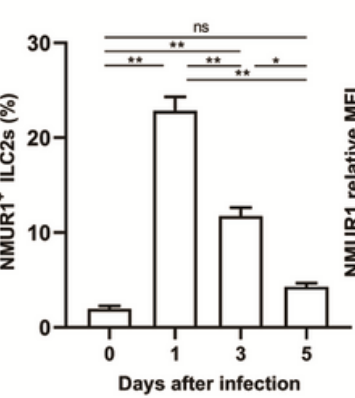

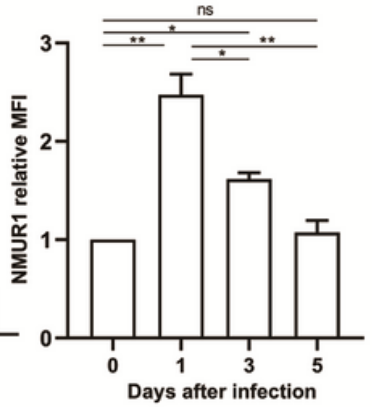

Figure 5

RSV infection enhances the expression of NMUR1 in the pulmonary ILC2s A Lymphocytes were isolated from the single cell suspensions of the lungs on day 3 after RSV infection by using lymphocyte isolation kit. The remaining cells were non-lymphocytes. ILC2s were sorted from the lymphocytes, and the rest were the other lymphocytes. Expressions of NMUR1 in these cell types were determined by Real-time PCR. $n=5$. B-C Real-time PCR (B) and Western blot (C) analyzed the expression of NMUR1 in pulmonary ILC2s after RSV infection. D The percentage of NMUR1 positive ILC2s as well as the relative MFI of NMUR1 on pulmonary ILC2s after RSV infection. Data are representative of at least three individual experiments, error bars represent $\mathrm{SEM}$; ${ }^{*} \mathrm{P}<0.05$, ${ }^{* *} \mathrm{P}<0.001$ by one-way ANOVA, ns not significant. 
A
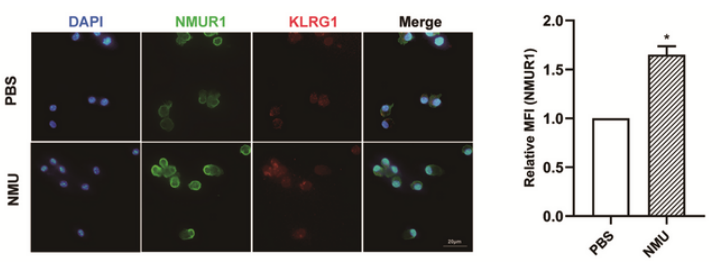

B
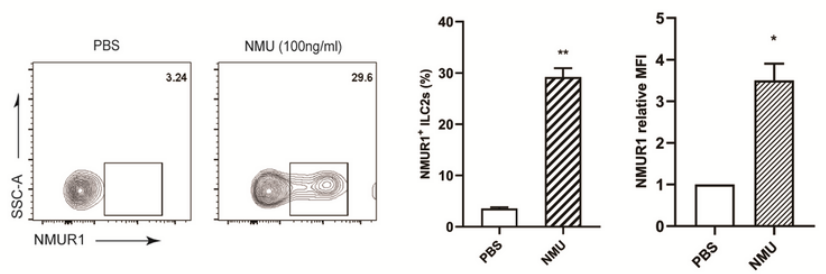

C
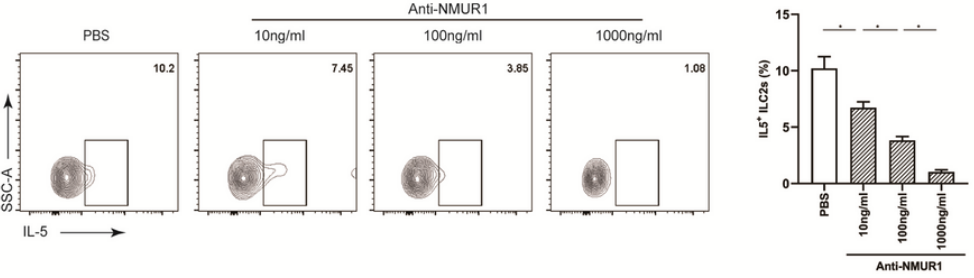

$\mathrm{D}$
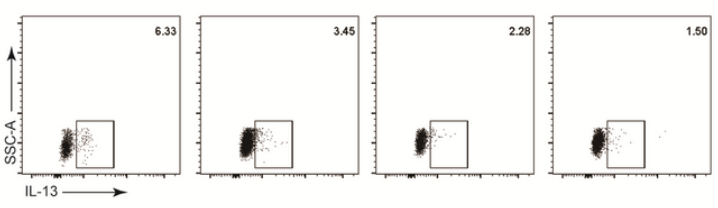

$\mathrm{E}$
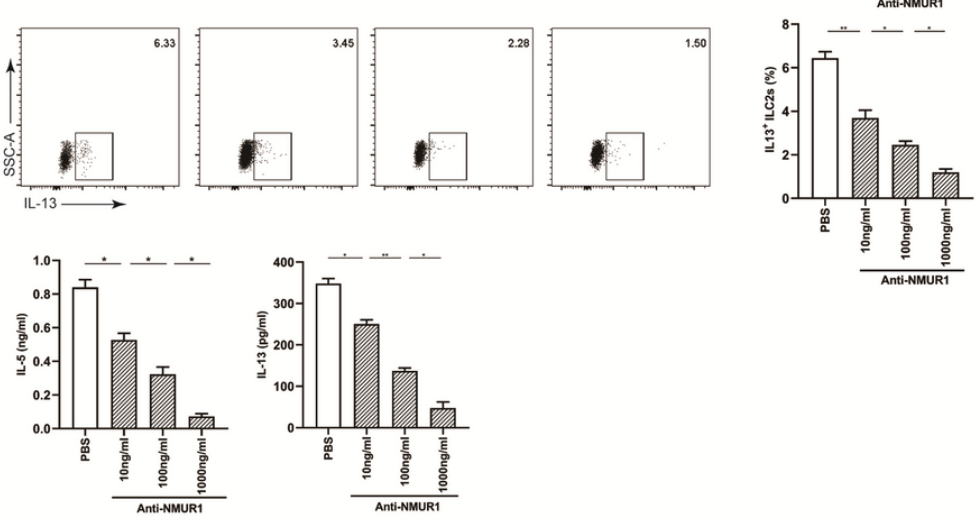

\section{Figure 6}

NMU stimulates pulmonary ILC2 activation via NMUR1. A ILC2s were sorted from the lungs of mice on day 3 after RSV infection, and cultured in vitro with

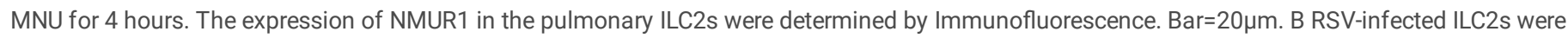
stimulated with or without NMU for 20 hours. Flow cytometric analysis of the percentage of NMUR1 positive ILC2s as well as the relative MFI of NMUR1 on ILC2s. C-E Sorted pulmonary ILC2s were stimulated with NMU for 20 hours in the presence of indicated concentrations of anti-NMUR1 antibodies. IL-5 (C) and IL-13 (D) producing ILC2s were determined by flow cytometry. $n=3$. E The concentration of IL-5 (left) or IL-13 (right) in the culture supernatant of ILC2s were detected by ELISA. Data are representative of at least three individual experiments, error bars represent $S E M$; ${ }^{*} P<0.05,{ }^{\star *} \mathrm{P}<0.001$ by two-tailed t-test $(\mathrm{A}, \mathrm{B})$ or one-way ANOVA (C, D, E). 
A

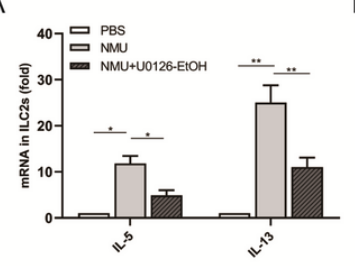

D

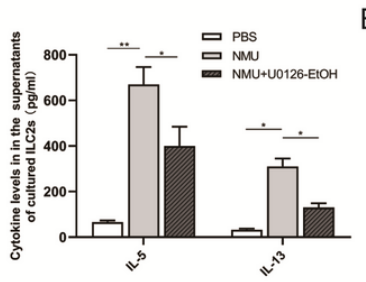

G

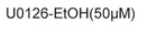
$\mathrm{NMU}(100 \mathrm{ng} / \mathrm{ml})$

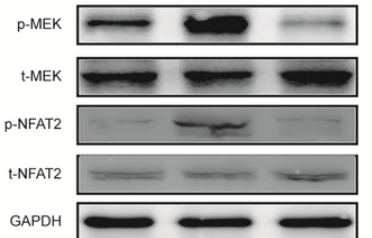

GAPDH

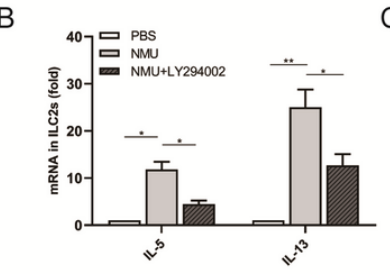

$\mathrm{E}$

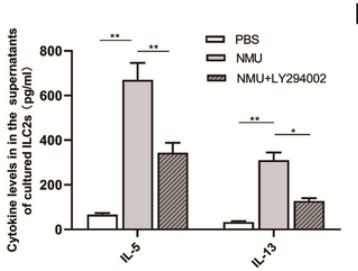

C

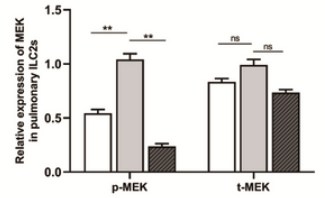

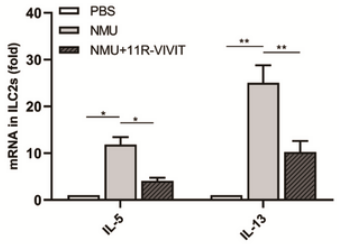

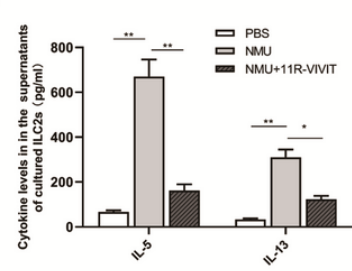

口U0126-EtOH(-) NMU(-) चU0126-EtOH(-) NMU(+) U0126-EtOH(+) NMU(+)

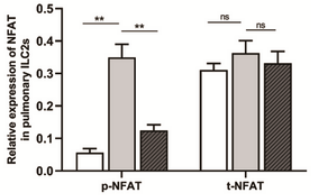

$\mathrm{H}$

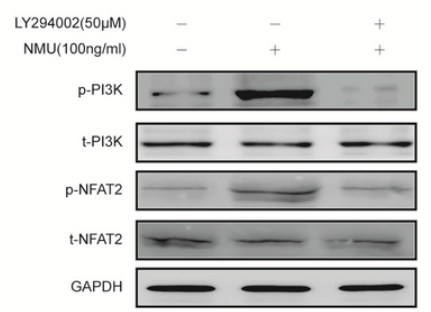

口 U0126-EtOH(-) NMU(-) चU0126-EtOH(-) NMU(+) U0126-EtOH(+) NMU(+)
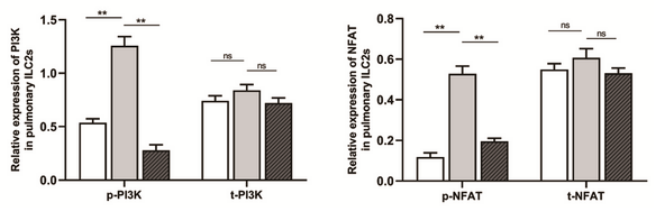

\section{Figure 7}

NMU regulates ILC2 activation via PI3K/NFAT and MEK/NFAT signals. ILC2s were sorted from the lungs of mice on day 3 after RSV infection, and co-cultured with NMU in vitro in the presence or absence of signal inhibitors. A-C Expressions of IL-5 and IL-13 by Real-time PCR in the presence of MEK inhibitor U0126EtOH (A), PI3K inhibitor LY294002 (B), and NFAT inhibitor 11R-VIVIT (C). D-E Concentrations of IL-5 and IL-13 in the culture supernatants of pulmonary ILC2s were determined by ELISA in the presence of MEK inhibitor U0126-EtOH (D), PI3K inhibitor LY294002 (E), and NFAT inhibitor 11R-VIVIT (F). G-H The expression of signal proteins in the isolated ILC2s were determined by Western blot under the conditions of the presence or absence of $\mathrm{U} 0126-\mathrm{EtOH}$ (G) or LY294002 (H). Data are representative of at least two individual experiments, error bars represent $S E M ;{ }^{*} P<0.05,{ }^{*} \mathrm{P}<0.001$ by two-way ANOVA, ns not significant. 
A

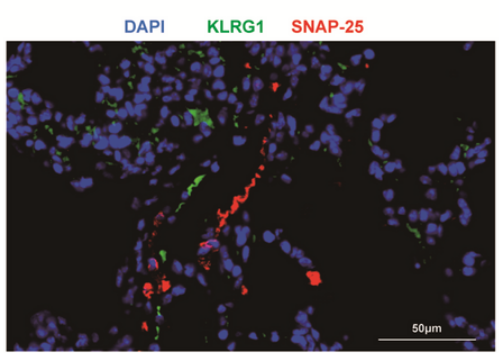

C

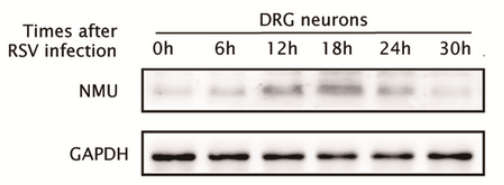

E

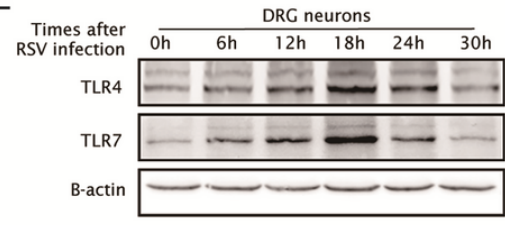

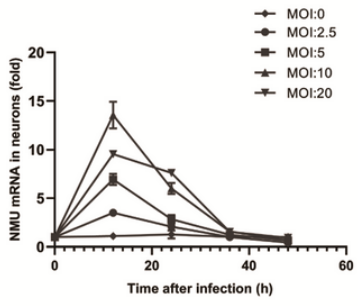
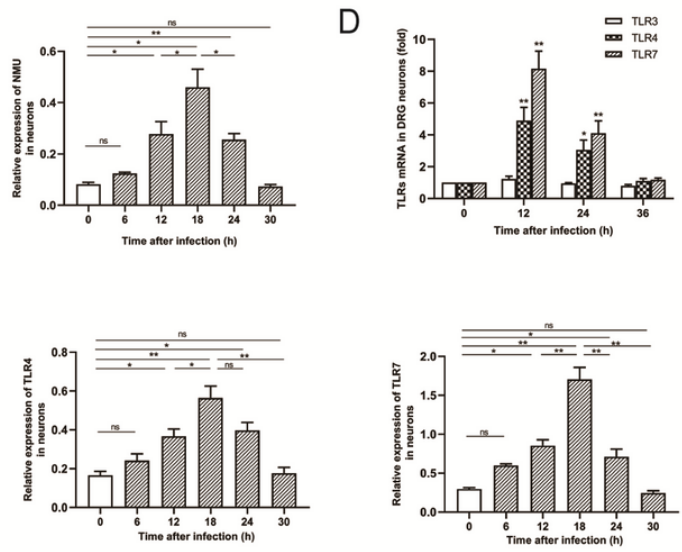

F
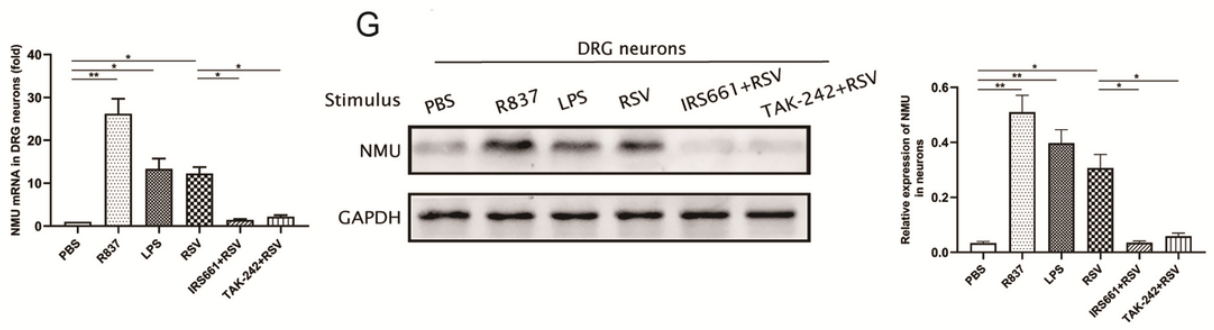

\section{Figure 8}

Neurons produce NMU in TLR4 and TLR7-dependent manners during RSV infection. A Immunofluorescent staining showed KLRG1+ ILC2s were adjacent to SNAP-25+ neurons. B RSV infection enhanced the expression of NMU in thoracic dorsal DRG neurons. The optimal infection dose was MOI:10. C Western blot of NMU in DRG neurons stimulated with RSV at different time points. $n=3$. D Real-time PCR showed the expressions of mRNA of TLR4 and TLR7 in DRG neurons after RSV infection (MOI:10). $n=3$. E Western blot of TLR4 and TLR7 in DRG neurons after RSV infection (MOI:10). $n=3$. F-G DRG neurons were infected with RSV at MOI:10 and co-cultured with TLR4 (LPS) or TLR7 (R837) agonist, and TLR4 inhibitor (TAK-242) or TLR7 antagonist (IRS661). The expression of NMU in the neurons were measured by Real-time PCR (F) and Western blot (G). $n=4$. Data are representative of three individual experiments, error bars represent $S E M ;{ }^{*} P<0.05,{ }^{*} \mathrm{P}<0.001$ by one-way ANOVA $(C, E, F, G)$ or two-way ANOVA (D), ns not significant.

\section{Supplementary Files}

This is a list of supplementary files associated with this preprint. Click to download.

- GraphicalAbstract.tif 